\title{
Relative Performance and Herding in Financial Markets
}

\author{
Emanuela Sciubba* \\ Faculty of Economics and Politics \\ University of Cambridge \\ and \\ Tinbergen Institute Rotterdam
}

January 2000

\begin{abstract}
We consider a stylised model of a financial market where assets are traded over 2 periods by three agents: two fund managers and a third large trader that represents the rest of the market. Fund managers are rewarded at the end of the second period by a bonus that is awarded to the manager that obtains the best cumulative performance. We show that, even when information is symmetric, inefficient herding may be observed as an equilibrium outcome. Herding among fund managers occurs when the size of the rest of the market is large, but finite, so that the impact of the herd on equilibrium prices is not negligible and indeed destabilising for asset prices.
\end{abstract}

JEL Classification: D40, D81, G10, G20.

Keywords: relative performance incentives, herding behaviour, price volatility.

Address for Correspondence: Emanuela Sciubba, Tinbergen Institute Rotterdam, Burgemeester Oudlaan 50, 3062 PA Rotterdam, The Netherlands. Phone: +31 10408 8953. Fax: +31 104089031. E-mail: sciubba@few.eur.nl

\footnotetext{
*I am deeply indebted to Luca Anderlini for his helpful guidance. I also benefited from discussions with Andrea Prat.
} 


\section{Introduction}

\subsection{Motivation}

The aim of this paper is to assess the influence of relative performance incentives on portfolio choices and on asset price dynamics. We ask whether, to what extent and with which consequences on asset prices, portfolio choices can be affected by the fact that professional money managers aim at maximising their relative, rather than absolute, performance.

Institutions hold an increasing portion of the value of equities. U.S. institutional investors, who owned only $6.1 \%$ of all equities in 1950 , now hold a total of $\$ 6.3$ trillion, equivalent to $49.6 \%$ of total outstanding equities ${ }^{1}$. Private and public pension funds alone hold together $\$ 3.1$ trillion, or $24 \%$ of equities. In Europe, the presence of institutional investors has not reached the same magnitude as in the U.S., but becomes increasingly conspicuous. In 1997, managed funds as a percentage of GDP were $70 \%$ in Italy, $59 \%$ in Germany, 93\% in France, 58\% in Spain, 197\% in the Netherlands, and 174\% in the U.K. ${ }^{2}$

Not only institutional investors hold the largest share of equities, but they also account for most of the trading volume with their trading activity; most institutional investors follow strategies of actively picking and trading stocks. As a result, large institutions have become increasingly important in determining market prices. Understanding the behaviour of stock prices therefore requires an understanding of the investment strategies of institutional investors.

The common belief is that institutional investors move in and out of stocks in a herd like manner. The idea that investors in general are influenced by the decisions of other investors dates back at least to Keynes' well known metaphor of the beauty contest ${ }^{3}$. In particular, when it comes to institutional investors, both casual empiricism and empirical evidence ${ }^{4}$ suggest $^{-}$ that their portfolio decisions display herding behaviour. Fund managers are aware of this and often bluntly admit to follow the crowd. Lakonishock et

\footnotetext{
${ }^{1}$ American data are from the New York Stock Exchange Fact Book 1998 [24].

${ }^{2}$ European data are from the Bank of Italy [2].

${ }^{3}$ Keynes [19] claimed that professional investors behave like judges in a beauty contest who vote on the basis of contestants' expected popularity with other judges rather than on the basis of their absolute beauty.

${ }^{4}$ See for example Lakonishock et al [20] and Grinblatt et al [14].
} 
al [20] report from an interview to a pension fund manager: "Institutions are herding animals. We watch the same indicators and listen to the same prognostications. Like lemmings, we tend to move in the same direction and at the same time. And that, naturally, exacerbates price movements". This latter observation is a major concern for practitioners and a challenge for financial economists: is herding behaviour destabilising for stock prices?

The issue does not have an obvious answer. In general terms, herding can be defined as behaviour patterns that are correlated across individuals. However, if many investors are purchasing promising "hot" stocks, correlated action might be due to the fact that they have all received positive relevant information on the same stocks. If so, investors are indeed making the market more efficient and speeding up the process of adjustment of prices to fundamentals. On the contrary, the notion of herding that one tends to associate with institutional investors is instead a negative one, that leads to systematic sub-optimal decision making .

Recent empirical studies ${ }^{6}$ have provided extensive evidence of inefficient herding behaviour by fund managers and have showed that the impact of institutional trading on stock prices has been often destabilising. Most of these studies have been motivated by the stock market crash of October 1987 and by the analysis of the crash itself made by the Brady Commission, that mainly blamed institutional investors that followed formal and informal dynamic hedging strategies, or "portfolio insurance" policies. As Lakonishock et al [20] point out, hedging strategies can clearly prove destabilising if they lead institutions to "jump on the bandwagon" and buy overpriced stocks and sell underpriced stocks, causing further divergence of prices from fundamentals.

Why do money managers herd? Grinblatt et al [14] study the correlation between the tendency of individual funds to herd and the fund performance and observe that the relation is indeed controversial. It is not at all clear that herding behaviour pays off in terms of absolute performance.

Two recent empirical studies have investigated the relation between performance and tendency to herd, but in the opposite direction: successful money managers will display a higher tendency to herd. Brown et al [5] and Chevalier and Ellison [7] test the hypothesis that managers with either

\footnotetext{
${ }^{5}$ See for example Bikhchandani et al [?].

${ }^{6}$ See, for example, Cutler et al [8], De Long et al [9], Grinblatt et al [14] and Lakonishock et al [20], on the 1987 crash. Frankel and Froot [11] studies herding behaviour in the foreign exchange market.
} 
extremely good or bad relative returns at mid-year, have incentives to alter the characteristics of their portfolios and change their risk profiles. Worst performing funds will take more risks, while better performing funds will tend to lock in their gains and index the market. They examine portfolio changes in the last quarter of the year and attribute this striking result to the strong relationship between the inflow of new investment in the fund and the fund's past relative performance. In order to maximise investment inflow, money managers have to maximise the ranking of their funds. The flow-performance relationship works as an implicit incentive contract for the fund manager. Finally, the current system of assessing and reporting fund performance on an annual basis causes the "end of the year" effect. Calendar year data appear to be the most generally available to consumers: listings of mutual funds, accompanied by calendar year returns, are published on an annual basis in many news, business and financial publications.

Ashton et al [1] report some interesting interviews with money managers. They admit a tendency to herd: "Fund managers as a group are complete wimps basically. There is fund manager risk aversion which I am sure you are becoming aware of, which is the desire to be in with the crowds, so that if everybody gets it wrong, then it doesn't matter" ([1], p.8). They confirm that relative performance is what matters: "The fact of the matter is, if you are in the top decile [...], you get patted on the head by the client. If you are in the bottom decile, you'll probably be fired. So the temptation is to be in the 3rd to the 7th and that means not deviating usually from the [index]. And because the [index] is what everybody else is doing; we're all chasing our own tail." ([1], p.8); "It does not matter what your absolute performance is. It doesn't matter if you're plus $200 \%$, if the market's plus $210 \%$. What I have to do is to ensure that this fund can act as a window for our sales force. It's got to be median or above, otherwise we can't sell it."([1], p.9).

In this paper we aim at providing a theoretical framework to study the relation between relative performance evaluation of fund managers, herding: behaviour and destabilisation of asset prices.

We consider a stylised dynamic model of a financial market where two assets, a risk-free and a risky asset, are traded over 2 periods by three agents: two fund managers and a third large trader that represents the rest of the market. Fund managers are rewarded at the end of the second period by means of a bonus that is awarded to the manager that obtains the best cumulative performance. The information on fundamentals is symmetric: all agents know the correct probability distribution over the return of the 
risky asset. Portfolio decisions are taken simultaneously by all agents at the beginning of each time period, and markets clear.

Our main result is that, even though information is symmetric, relative performance incentives serve as a coordination device for fund managers to herd. Herding can be observed as an equilibrium outcome under interesting economic circumstances. After a good realisation of the risky asset and if the risky asset is still likely to yield a high payoff in the future, fund managers may herd on the safe asset. After a bad realisation of the risky asset and if the risky asset is still likely to yield a low payoff in the future, fund managers may herd on the risky asset. Clearly the herding behaviour we may obtain is inefficient. Relative performance evaluation might fail to provide the right incentives, and, as a result, fund managers might not pursue expected wealth maximisation.

More in detail, fund managers play a two-stage game that we solve backwards. The game clearly displays a multiplicity of equilibria. However we can conveniently distinguish between two types of equilibrium paths, according to players' behaviour in the first stage of the game. If the two (identical) fund managers start off investing in the same asset, then they reach the end of the first stage with identical wealth. Hence the game that they face in the second stage is symmetric. In order to become leader and win the bonus, in the second stage they will both prefer to play different strategies, so that each of them has a positive chance of winning the bonus. On these equilibrium paths we observe both fund managers investing in the asset with the higher expected return in the first stage.

Suppose, instead, that fund managers choose different strategies in the first stage of the game. When they reach the beginning of the second stage, one of the two fund managers will display superior interim performance. Hence, in the second stage, the game between fund managers is asymmetric and optimal strategies differ across the two players. The laggard wants to differentiate himself as much as possible from the leading manager, and the leading manager wants to imitate the follower. However, if the wealth gap between the two funds is large enough, then the laggard may not have any possibility of catching up and will find it optimal to herd with the leader.

We concentrate on this type of equilibrium paths (with asymmetric play in the first stage) and we characterise the conditions that lead to herding as an equilibrium outcome in the second stage. If the risky asset paid a high payoff in the first stage, herding in the safe asset may occur in the second stage if the probability of a good realisation of the risky asset in the next 
stage is high enough. If the risky asset paid a low payoff in the first stage, herding in the risky asset may occur in the second stage if the probability of a high realisation of the risky asset in the next stage is sufficiently low. Moreover, interestingly enough, inefficient herding occurs when the size of the rest of the market is large, but finite, so that the impact of herding on equilibrium prices is not negligible and we can conclude that the presence of institutional investors is indeed destabilising for asset prices.

This result proves particularly surprising in the light of the fact that we obtain herding behaviour and price destabilisation, without assuming any degree of asymmetric information. Clearly the presence of information asymmetries, as in Gennotte and Leland [12], would reinforce our result.

\subsection{Related Literature}

In this paper we build a stylised financial market model that encompasses relative performance incentives, herding behaviour and excess volatility in asset prices. Thus, there are at least three strands of literature that are related to the present paper: the literature on the economic rationale and the effects of relative performance evaluation; the vast literature on herding in financial markets; and finally the literature on excess volatility and price crashes.

The economic rationale for relative performance evaluation is to be found in the literature on moral hazard in teams. It is well-known that relative performance evaluation can enhance efficiency in a multi-agent single-principal setting. Mookherjee [22] considers the situation where the agent's output depends not only on effort and idiosyncratic noise, but also on a common shock experienced by other agents. In these circumstances the optimal contract is based on relative performance evaluation. Nalebuff and Stiglitz [23] consider a rank order tournament, i.e. a compensation scheme in which contestants' rewards are based on their ordinal positions alone and not on the size of their output, and show that such a structure is preferable to individualistic reward structures when environmental uncertainty is large. They prove that, in the limit, as the number of contestants becomes large, the outcome of a rank order tournament approximates first best. Gibbons and Murphy [13] find similar properties for a relative performance evaluation scheme for Chief Fxecutive Officers. They also suggest that relative performance evaluation distorts workers' incentives whenever agents can take actions that affect the average output of their reference group; for example, when they get to choose 
their co-workers, or when they can collude.

Most of these contributions, however, analyse the agency problem in a static setting. Meyer and Vickers [21] show that, in a dynamic setting, comparative performance evaluation has an ambiguous impact, and that it is not guaranteed that it enhances efficiency. Indeed, some recent work proves that relative performance evaluation might be undesirable in specific dynamic settings; for example, when agents not only choose the level of effort (expected return) but also the riskiness of their actions (variance). This is particularly relevant for money managers, that clearly control both the expected return and the risk of their portfolios. Hvide [16] studies a situation where agents also get to decide on the riskiness of their actions. He proves that a contract that ranks agents according to the relative closeness of their output to a benchmark (rather than ranking them against each other) can be beneficial to limit the risk that the agent might be willing to take. He argues that this could serve as a rationale for the fact that sometimes modest outcomes are more highly rewarded than very high performances.

Hvide and Kristiansen [17] also look at the efficiency of relative performance evaluation when agents can decide on risks to be taken. Differently from [16], they analyse how well contests select talented agents, rather than how well contests provide the right incentives to elicit effort. Their main result is rather counterintuitive: a better quality of the pool of contestants might reduce the efficiency of the contest. This happens because a more competitive tournament (a tournament with participants of higher quality) induces agents to adopt riskier strategies, which might harm the selection of high quality individuals. Riskier projects create more noise in the selection contest, thereby reducing the informativeness of the rank.

Finally, Palomino and Prat [25] develop a general model of delegated portfolio management with the feature that the agent can control the riskiness of the portfolio. In the static case, the optimal contract is a bonus contract, based on relative performance. In the multiperiod case, the bonus contract is no longer first-best. The intuition for their result lies in the fact that in a dynamic setting the agent can revise his portfolio choice after observing his performance at intermediate stages. This is particularly true if we believe that investors can evaluate the agent's performance less often that he can revise his portfolio decisions. The same idea is in the empirical work by Chevalier and Ellison [7]: mutual fund managers control investment volatility continuously, while investors receive performance information at discrete time intervals. 
In the setting that we investigate, the results by Palomino and Prat [25] are put to work in a market setting. We show that a bonus contract may indeed prove inefficient and we characterise the type of distortion that it may cause both on portfolios and on asset prices.

Within the literature on relative performance evaluation, some contributions have also looked at the problem of information acquisition. Eichberger et al [10] look at a model where fund managers are rewarded on the basis of relative performance and have to decide whether to gather information and how to allocate their portfolios. They find that there are multiple equilibria, so that relative performance evaluation might or might not provide the right incentives. Gümbel [15] considers a similar model in a market setting. Interestingly enough, he obtains efficient herding as an equilibrium outcome. Herding in information acquisition is induced by the principal (agents want to acquire the same piece of information as their competitors) and it increases the efficiency of prices.

There is a clear similarity and several important differences between Gümbel [15] and the present paper. In [15], the author obtains herding in equilibrium as an effect of relative performance evaluation. However, in [15] herding is in the information acquisition policy, while we obtain herding in portfolios. Moreover, in [15] herding is efficient and makes asset prices more informative, while in the present paper we mainly concentrate on inefficient herding that drives asset prices further away from fundamentals. Finally, the market structure in [15] is an oligopoly à la Kyle, while we look at a competitive market.

This paper is very close in spirit to some recent work by Cabral [6] and Palomino and Prat [26]. Cabral considers an infinite-period race where players choose between alternative growth technologies. He provides sufficient conditions under which, in equilibrium, the leader chooses a safe technology and the laggard a risky one; and conditions under which the laggard prefers to differentiate from the leader whereas the leader prefers to imitate the follower. Palomino and Prat [26] analyse competition over two investment periods between two money managers that have ranking-based objectives. They derive conditions on intermediate performances under which managers play conservative and overly-risky strategies and find that, if the difference in performances in the first period is large, the interim winner has incentives to minimise the level of risk undertaken in the second period to lock in his gain of the first period.

Our paper shares some of the intuition for its results with [6] and [26]. 
However, we adapt their analysis to a financial market setting, with the main difference that [6] and [26] only analyse the game between contestants, while we also look at the market equilibrium and at the effects of contestants' behaviour on endogenous asset prices.

The second strand of literature that is related to the present paper is the literature on herding behaviour. The research on herding has polarised in two different views: a non-rational view, that attributes inefficient herding behaviour to imitation and mimicry instincts and to investors' psychology; and a rational view, that shows that inefficient herding may obtain as an equilibrium outcome of a game played by fully rational investors. The rational view (which this paper adopts) has centered on three different approaches, than can be summarised as follows: presence of payoff externalities, informational cascades and principal-agent models. An example within the first approach is given by models of information acquisition. Agents might herd on information acquisition as they find it worthwhile to acquire further information only if other agents also $\mathrm{do}^{7}$. In the model we propose there is neither information acquisition externalities nor other payoff externalities, but herding is still obtainable as an equilibrium outcome.

The second approach provides the most common explanation of herding. It builds on the idea that agents gain useful information from observing previous agents' decisions, to the point that they optimally and rationally completely ignore their own private information, and herd. Informational cascades have been introduced by Bikhchandani et al [3] and Welch [30]. In the present paper decision making is simultaneous and information is symmetric, so that social learning and informational cascades have no role.

Here, herding occurs because of relative performance incentives, so that our framework is closer to the third approach, where herding is obtained as an outcome of agency problems. A similar perspective is in Scharfstein and Stein [27]. They develop a model where managers are concerned about their reputation and therefore simply mimic the investment decisions of other managers, ignoring substantial private information. A "sharing the blame" effect drives them to herd. A crucial feature of their model is that they assume that a manager does not know his quality; however, he knows that if he is smart he will observe the same signal as other smart managers in the market.

A similar setting is developed by Zwiebel [31]. He obtains the same result

\footnotetext{
${ }^{7}$ See, for example, Gümbel [15].
} 
as Scharfstein and Stein [27], but with a different information structure. He assumes that managers know their own ability; however, because of reputational concerns, they still refrain from undertaking innovations that stochastically dominate the industry standard and get locked in inferior equilibria. Zwiebel calls this type of behaviour "corporate conservatism".

The main differences between Scharfstein and Stain [27] and Zwiebel [31] and the present paper are the following: first of all, herding behaviour in our setting does not stem from reputational concerns, but from relative performance evaluation. We assume that fund managers have the same ability and the same quality of information. Secondly, and most importantly, we analyse a market setting, where the effect of herding on asset prices is also studied.

Finally, the present paper is also related to the literature on price crashes and in particular to the literature that studies the role of the behaviour of institutional investors in price crashes. Gennotte and Leland [12] develop a financial market model where a relative small amount of dynamic hedging strategies can cause asset prices to fall significantly. The driving force of their result lies in the fact that, even if there are only a few hedgers, there are traders who infer information from market prices. As a result, the effects of hedging activity on asset prices are magnified. A similar setting is in Jacklin et al [18]. They examine the role played by formal and informal dynamic hedging strategies in the market crash of October 1987. They provide a theoretical underpinning for the stylised fact that, in the period prior to the crash, prices are higher than fundamentals would imply. The intuition for their result is that information on the extent of portfolio insurance is revealed only slowly through time, so that, prior to a crash, the market is indeed underestimating the size of hedgers that are active in the market. When the amount of portfolio insurance is fully revealed, the price falls.

In the present paper we obtain excess volatility. The driving force in our case is not the presence of hedgers, but the custom of rewarding money managers according to their relative performance.

\subsection{Overview}

The structure of the paper is as follows. In section 2 we present the basic structure of our model in a simplified setting: we look at a two-period investment model where investors choose between alternative linear technologies whose returns are assumed to be exogenous; sub-sections 2.1 and 2.2 characterise respectively the equilibria of the game played by investors in the last 
and interim stages; finally sub-section 2.5 highlights some of the features of this simple technology adoption model and suggests how to extend it to a financial market model, where asset prices - here returns from alternative technologies - are indeed endogenous.

In section 3 we extend our analysis to a financial market model and we present our main results. In particular, in sub-section 3.1 we look at the game played by fund managers in the interim stage; in sub-section 3.2 we prove existence and uniqueness of a market clearing equilibrium for each stage of the game; finally, in sub-section 3.3 we present the main results of our analysis: we characterise sufficient conditions for inefficient herding to be obtained as an equilibrium outcome in the second stage of the game and we show that the herding behaviour thus obtained is indeed destabilising for asset prices.

In section 4 we examine the robustness of our analysis in less simplified environments and we suggest directions for future research.

Section 5 concludes the paper.

For ease of exposition, all proofs are in the appendix.

\section{A Model with Linear Technologies}

Consider a simple two-period investment model where investors, at the beginning of each time period, choose between two alternative technologies to store wealth: a safe technology $A$ and a risky technology $B$. Both technologies are linear, so that, if wealth available for investment at the beginning of period $t$ (end of period $t-1$ ), $w_{t-1}$, is invested in the safe technology $A$, the total return at the end of period $t$ is:

$$
w_{t}=A w_{t-1}
$$

If the risky technology $B$ is chosen for investment in period $t$, then the investment income at $t$ is:

$$
w_{t}=\widetilde{B}_{t} w_{t-1}
$$

where $\widetilde{B}_{t}$ is equal to $B^{H}$ with probability $p>0$ and to $B^{L}$ with probability $(1-p)>0$. We assume that $B^{L}<A<B^{H}$.

There are two professional investors that manage identical wealth endowments at $t=0$, both normalised to be equal to 1 . Investors choose technologies twice (at $t=0$ and at $t=1$ ) and cash investment incomes twice 
(at $t=1$ and $t=2$ ). Technology choices last for one period only, so that investors may or may not adopt the same technology twice. Investors have no other way to store wealth, so that the initial endowment is entirely invested in the technology chosen for the first period. Similarly, the investment income from the first period is entirely invested in the technology chosen for the second period. We also assume that investors cannot hold "portfolios" of technologies, but only invest in one technology at a time. In what follows (see subsection 2.4), we show that this assumption is without loss of generality in our setting: if investors only care about their ranking, they prefer to hold "extreme portfolios", where only one technology is represented ${ }^{8}$.

The economic agents that get to choose which technology to adopt, are indeed professional investors managing clients' money, rather than their own. Hence we assume that they do not derive utility directly from the investment incomes that they obtain on behalf of their clients. Investors in our model only care about their compensation: the investor that ends up with the largest wealth at $t=2$ obtains a strictly positive bonus; in case of tie, nobody gets the bonus ${ }^{9}$. This latter feature implies that investors will never want to adopt the same sequence of technologies, with the result that a tie will never be observed in equilibrium.

\subsection{The Bonus Stage}

In the simple world we are describing, fund managers play a two-stage game, where payoffs (the bonus) are distributed only at the end of the second stage. Players aim at reaching the leadership position in order to win the bonus. We can solve the game backwards: call the two stages of play interim and bonus stage respectively, and focus on the bonus stage first.

We need to fix an history for the interim stage. Suppose that investors choose different assets in the first stage of play, so to reach the bonus stage with "leader" and "follower" roles. Moreover, consider the case $\widetilde{B}_{1}=B^{H}$ first. After a "good" realisation of the risky technology in the interim stage,

\footnotetext{
${ }^{8}$ When investors also care about their absolute performance, they have an incentive to diversify. However, in section 4 we argue that how our main results should prove robust to such changes in the model.

${ }^{9}$ This assumption simplifies our analysis. It also finds support by the empirical evidence: Brown et al [5] and Chevalier and Ellison [7] show that the fund's new money flowperformance relationship, that acts as an implicit incentive contract for the fund manager, is convex. "Real" leaders are more generously compensated.
} 
at $t=1$, the player who invested in technology $B$ is the leader and the player who invested in the safe technology $A$ is the follower. The bonus subgame is the game that leader and follower play against each other in the bonus stage. Let us call player $i$ and player $j$ the leader and the follower at date $t=1$, respectively. Also we will follow the convention of having the interim follower as first (row) player and the interim leader as second (column) player.

If, in the bonus stage, both managers invest in the same technology (strategy profiles $A A$ and $B B$ ), then clearly the interim leader (player $i$ ) will win the bonus with probability 1 . If they invest in different technologies then the interim follower might (or might not) catch up with the interim leader. In particular, if, in the bonus stage, follower and leader invest in the risky and safe technologies respectively (strategy profile $B A$ ), player $i$ 's wealth is equal to $B^{H} A$ and player $j$ 's wealth is equal to $A \widetilde{B}_{2}$. As a result, if in the second stage $\widetilde{B}_{2}=B^{H}$, we have a tie (and nobody gets the bonus), if $\widetilde{B}_{2}=B^{L}$ then player $i$ wins the bonus. If we normalise the size of the bonus to 1 , expected payoffs to the interim follower and leader, with the strategy profile $B A$, are 0 and $(1-p)$ respectively. One last case to consider is the strategy profile $A B$; when the interim follower invests in the safe technology and the interim leader in the risky one, then the follower might indeed have the chance to outperform the leader. The outcome will depend on our parametric assumptions. If $A^{2}>B^{H} B^{L}$ then the follower will outperform the leader and win the bonus. If, on the contrary, $A^{2}<B^{H} B^{L}$, then the interim leader will stay leader and get the bonus. Finally, if $A^{2}=B^{H} B^{L}$, we have a tie and none of the investors wins the bonus.

The bonus subgame that interim leader and follower play, under these three different parametric assumptions, can be summarised by the following payoff matrices, where bold payoffs identify equilibria:

1. If $A^{2}>B^{H} B^{L}$ :

$\begin{array}{lllll}\text { Follower } \backslash \text { Leader } & A & & B \\ A & \mathbf{0} ; & \mathbf{1} & 1-p ; p \\ B & 0 ; & 1-p & 0 ; & 1\end{array}$

2. If $A^{2}<B^{H} B^{L}$ :

$\begin{array}{lcccc}\text { Follower } \backslash \text { Leader } & A & & B & \\ A & \mathbf{0} ; & \mathbf{1} & \mathbf{0} ; & \mathbf{1} \\ B & 0 ; & 1-p & \mathbf{0} ; & \mathbf{1}\end{array}$


3. If $A^{2}=B^{H} B^{L}$ :

$\begin{array}{lcccc}\text { Follower } \backslash \text { Leader } & A & & B & \\ A & \mathbf{0} ; & \mathbf{1} & 0 ; & p \\ B & 0 ; & 1-p & \mathbf{0} ; & \mathbf{1}\end{array}$

In case (1), the bonus subgame has a unique Nash Equilibrium, $A A$. When players reach the second stage of the game with non-identical wealth, after a good realisation of the risky technology in the first stage, both players will play safe in the bonus stage and invest their whole endowment in the safe technology. In case (2), Nash Equilibria for the bonus subgame (in pure strategies) are: $A A, A B, B B$. Players will either both invest in the safe technology, or both in the risky technology, or, finally, both adopt the same technologies they had chosen in the interim stage (i.e. leader and follower will respectively invest in the risky and the safe technology). In case (3), Nash Equilibria for the bonus subgame (in pure strategies) are: $A A, B B$. Once again, in the second stage of play, investors will adopt the same technology in equilibrium.

Similarly, we can examine what is the play in the bonus stage, after the history $\widetilde{B}_{1}=B^{L}$ for the interim stage. Once again, suppose that investors choose different assets in the first stage of play, so to reach the bonus stage with "leader" and "follower" roles. In this case, we call player $i$ the player who invested his endowment in the safe technology in the interim stage, so that $i$ is the interim leader at $t=1$. We call $j$ the player who invested his wealth in the risky technology in the interim stage, so that $j$ is the interim follower at $t=1$. In the bonus stage, if both players invest in the same technology, clearly player $i$ (the interim leader) will stay leader and win the bonus with probability 1 . If they invest in different technologies, then the interim follower, under some conditions, outperforms the interim leader. Like before, different parametric assumptions imply different sets of equilibria for the bonus subgame (equilibrium payoffs are in bold):

1. If $A^{2}<B^{H} B^{L}$ :

$\begin{array}{lcccc}\text { Follower } \backslash \text { Leader } & A & & B & \\ A & 0 ; & 1 & 0 ; & p \\ B & p ; & 1-p & \mathbf{0} ; & \mathbf{1}\end{array}$


2. If $A^{2}>B^{H} B^{L}$ :

$\begin{array}{lllll}\text { Follower } \backslash \text { Leader } & A & & B & \\ A & \mathbf{0} ; & \mathbf{1} & 0 ; & p \\ B & \mathbf{0} ; & \mathbf{1} & \mathbf{0} ; & \mathbf{1}\end{array}$

3. If $A^{2}=B^{H} B^{L}$ :

$\begin{array}{lcccc}\text { Follower } \backslash \text { Leader } & A & & B & \\ A & \mathbf{0} & \mathbf{1} & 0 ; & p \\ B & 0 ; & 1-p & \mathbf{0} ; & \mathbf{1}\end{array}$

As one might have expected, the results we obtain are symmetric to what we found in the previous case above. In case (1), the bonus subgame has a unique Nash Equilibrium, $B B$. In the last stage of game, if players have non-identical wealth and after a bad realisation of the risky asset in the interim stage, both players play risky and invest their whole endowment in the risky technology. In case (2), Nash Equilibria for the bonus subgame (in pure strategies) are: $A A, B A, B B$. Players will either both invest in the safe technology, or both in the risky technology, or, finally, both adopt the same technologies they had chosen in the interim stage (i.e. leader and follower will respectively invest in the risky and the safe technology). In case (3), Nash Equilibria for the bonus subgame (in pure strategies) are: $A A, B B$. Once again, in the second stage of play, investors will adopt the same technology in equilibrium.

Let us now consider a different history for the interim stage. Suppose that investors choose the same technology to store wealth in the first period. The two fund managers (identical at $t=0$ ) will reach the bonus subgame with identical wealth endowments. Since there is no "interim leader", investors play a symmetric subgame in the bonus stage, where they both try and reach for the leadership.

Recall that we are assuming that in case of tie nobody gets the bonus; fund managers have to outperform their opponents in order to qualify for the reward. As a result, in equilibrium investors will choose to store wealth in different technologies. Payoffs for the bonus subgame, when players have identical wealth, can be summarised by the following matrix, where equilibrium payoffs are denoted in bold.

$\begin{array}{llll}\text { First player } \backslash \text { Second player } & A & & B \\ A & 0 ; & 0 & \mathbf{1}-\mathbf{p} ; \mathbf{p} \\ B & \mathbf{p} ; \quad \mathbf{1}-\mathbf{p} & 0 ; & 0\end{array}$


In this case the (pure strategies) Nash Equilibria of the bonus subgame are $A B$ and $B A$.

Summarising, depending on parametric assumptions, the bonus subgame that follows an asymmetric play in the interim stage, may display one, two or three Nash Equilibria. All equilibria are payoff equivalent. In particular it is always possible for the interim leader to keep his leadership in equilibrium and win the bonus with probability one at the end of the second stage. Whenever investors play asymmetrically in the interim stage, the actual bonus winner is in fact determined by the end of the first period.

On the contrary, when investors play simmetrically in the first period, the bonus winner is to be determined in the second stage of the game. In this case, the bonus subgame always has two Nash Equilibria. Both equilibria are asymmetric and they are not payoff equivalent. Depending on how likely the risky asset is to yield a high payoff (the value of the probability $p$ ), fund managers will be better off in one equilibrium rather than in the other.

\subsection{The Interim Stage}

Solving the game by backward induction, we can now ask which strategies will fund managers optimally choose in the interim stage, given the equilibrium outcomes of the following subgames.

The payoffs to fund managers who invest asymmetrically in the first stage (strategy profiles $A B$ and $B A$ ) are easy to compute. When investors play different strategies in the first stage of the game, the interim leader is guaranteed to be bonus winner, so that expected payoffs to each of the players are indeed equal to the probabilities of becoming interim leaders. As a result, the expected payoff to a fund manager that invests in the risky technology, while his opponent is investing in the safe technology, is equal to $p$; his opponent's expected payoff is $(1-p)$. These payoffs can be summarised by the following (incomplete) payoff matrix.

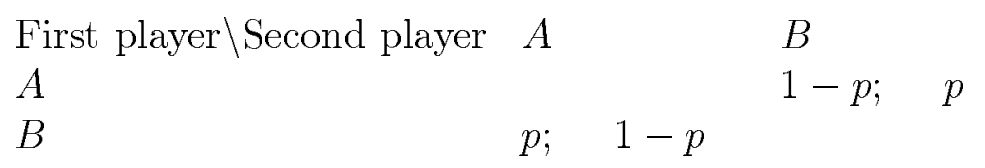

When investors choose the same technology in the first stage of play (strategy profiles $A A$ and $B B$ ), the bonus subgame displays two Nash Equilibria which are not payoff equivalent. Hence, expected payoffs in the interim 
stage are conditional on the specific equilibrium that prevails in the second stage of the game. We can therefore distinguish between four different cases.

1. Suppose, first, that after both $A A$ and $B B$ in the first stage, the equilibrium $A B$ prevails in the second stage of game, so that the first player wins the bonus with probability $(1-p)$ and the second player wins the bonus with probability $p$. In the interim stage the payoff matrix would look as follows:

$\begin{array}{llll}\text { First player } \backslash \text { Second player } & A & & \\ A & 1-p ; \quad p & 1-p ; & p \\ B & p ; 1-p & 1-p ; & p\end{array}$

The (pure strategies) Nash Equilibria of the game played in the interim stage depend on the value of $p$. If $p$ is small (in particular, if $p<1 / 2$ ), then $A A$ and $A B$ are equilibria. If $p$ is large (in particular, if $p>1 / 2$ ), then $B B$ and $A B$ are equilibria.

2. Suppose, on the opposite, that after both $A A$ and $B B$ in the first stage, the equilibrium $B A$ prevails in the second stage of game, so that the first player wins the bonus with probability $p$ and the second player wins the bonus with probability $(1-p)$. In the interim stage the payoff matrix would look as follows:

$\begin{array}{llll}\text { First player } \backslash \text { Second player } & A & & \\ A & p ; & 1-p & 1-p ; p \\ B & p ; & 1-p & p ; 1-p\end{array}$

The (pure strategies) Nash Equilibria of the game played in the interim stage depend on the value of $p$. If $p$ is small (in particular, if $p<1 / 2$ ), then $A A$ and $B A$ are equilibria. If $p$ is large (in particular, if $p>1 / 2$ ), then $B B$ and $B A$ are equilibria.

3. Suppose, now, that after $A A$ in the first stage, the equilibrium that prevails in the second stage is $A B$ and that, after $B B$ in the first stage, the equilibrium that prevails in the second stage is $B A$. In the interim stage the payoff matrix would look as follows:

$\begin{array}{lll}\text { First player } \backslash \text { Second player } & A & B \\ A & 1-p ; \quad p & 1-p ; \quad p \\ B & p ; 1-p & p ; 1-p\end{array}$


The (pure strategies) Nash Equilibria of the game played in the interim stage depend on the value of $p$. If $p$ is small (in particular, if $p<1 / 2$ ), then $A A$ and $A B$ are equilibria. If $p$ is large (in particular, if $p>1 / 2$ ), then $B B$ and $B A$ are equilibria.

4. Finally, suppose that after $A A$ in the first stage, the equilibrium that prevails in the second stage is $B A$ and that, after $B B$ in the first stage, the equilibrium that prevails in the second stage is $A B$. In the interim stage the payoff mtrix would look as follows:

$\begin{array}{lcccc}\text { First player } \backslash \text { Second player } & A & & B & \\ A & p ; & 1-p & 1-p ; & p \\ B & p ; & 1-p & 1-p ; & p\end{array}$

The (pure strategies) Nash Equilibria of the game played in the interim stage depend on the value of $p$. If $p$ is small (in particular, if $p<1 / 2$ ), then $A A$ and $B A$ are equilibria. If $p$ is large (in particular, if $p>1 / 2$ ), then $B B$ and $A B$ are equilibria.

Summarising, we find that in the interim stage both symmetric and asymmetric play can be observed in equilibrium. Whenever we observe symmetric play $(A A$ or $B B)$, the parameter that is crucial in determining whether fund managers will both invest in the safe technology or in the risky one, is the probability that the risky technology yields a high payoff (the value of $p$ ). If $p$ is large (high payoff is very likely), both fund managers will invest in the risky technology and $B B$ will be observed in equilibrium. If $p$ is small (high payoff very unlikely), both fund managers will invest in the safe technology and $A A$ will be observed in equilibrium.

Whenever asymmetric play $(A B$ or $B A$ ) is observed in equilibrium, the probability $p$ plays no role and the only determinant that implies one equilibrium rather than the other is the punishment in case of deviations. For example, a player that unilaterally deviates from $A B$ (to $A A$ or $B B$ ) and that faces the (credible) punishment $A B$ in the second stage of game, leading him to an identical expected payoff, has no incentive to deviate.

\subsection{Equilibrium Paths}

In the previous two subsections we have solved the two stage game between fund managers by backward induction. We can now finally summarise and characterise the whole equilibrium paths. 
The game between fund managers clearly displays a multiplicity of equilibria. However we can conveniently distinguish between two types of equilibrium paths, according to players' behaviour in the first stage of the game.

1. If the two players invest in the same technology in the interim stage (strategy profiles $A A$ and $B B$ ), then they will invest in different technologies in the bonus stage. In particular, if the risky technology has a higher expected return than the safe technology (i.e. $p$ large enough), then both players will invest in the risky technology in the first stage. Hence we will observe $B B$ in the first period, followed by either $A B$ or $B A$ in the bonus stage. On the contrary, if the safe technology has a higher expected return than the risky technology (i.e. $p$ small enough), then both players will invest in the safe technology in the first stage. Hence we will observe $A A$ in the first period, followed by either $A B$ or $B A$ in the bonus stage.

2. If the two players invest in different technologies in the interim stage (strategy profiles $A B$ and $B A$ ), then in the bonus stage we might have either one, or two or even three payoff equivalent Nash Equilibria, depending on parameter values and on the realisation of the technology in the interim stage. Interestingly enough one notices that the only equilibrium outcome which all parametric specifications have in common is such that in the second period investors herd in the asset which has been the least successful in the first period. In particular, fund managers herd in the safe asset in the bonus stage, if the risky asset has paid a high payoff in the interim stage. On the contrary, they herd in the risky asset in the bonus stage, if the risky asset has paid a low payoff in the interim stage. Moreover, the herd that occurs in the second stage of play, unlike the herd that one could observe in the first stage of play, is not necessarily efficient. In fact, the expected return of the risky technology plays no role in such an equilibrium outcome and indeed both players might find themselves optimally investing in the risky technology even when it yields a lower expected return than the safe technology.

\subsection{Do Fund Managers Hold "Extreme" Portfolios?}

In the model described in this section, we have assumed that fund managers can either invest in the safe technology or in the risky technology: they 
cannot invest their endowments in a diversified portfolio of technologies. We can show that, so long as investors are rewarded on the basis of their relative performance, this assumption is without loss of generality. Namely, even if allowed to hold portfolios of technologies, they would optimally choose "extreme" portfolio compositions and invest their entire endowments in only one of the available technologies.

For example, let us consider the bonus subgame that follows asymmetric behaviour in the interim stage, after a good realisation of the risky technology in the interim stage. We know from our previous analysis that, when fund managers cannot diversify, under the parametric condition $A^{2}>B^{H} B^{L}$, the unique Nash Equilibrium of the bonus subgame is $A A$, i.e. both players will choose the safe technology. We can easily prove that, even when we assume that money managers can diversify their portfolios (and hence consider a larger strategy space for the two players), under the same parametric conditions, "all the money in safe" is still a Nash Equilibrium of the extended subgame.

Suppose, in fact, that the interim follower is having all his endowment invested in the safe technology. It is clearly a best reply for the interim leader to mimic his opponent's portfolio. Hence "all the money in safe" is what the leader will rationally choose to do. Suppose, now, that the interim leader is having all his endowment invested in the safe technology; does the interim follower have an incentive to deviate from "all the money in safe"? If he diverts part of his resources to the risky technology, he cannot do any better, as our parametric conditions guarantee that catching up with the interim leader is excluded anyway. If we assume that there is even a small lexicographic cost in investing in two technologies (or assets) rather than one, then clearly the follower will strictly prefer to herd with the leader, rather than holding a diversified portfolio that costs him more and yields the same expected bonus.

Moreover, the assumption of a small lexicographic cost for diversification implies that (for example in the same parametric case we have considered above) "all the money in safe" for both fund managers is the unique Nash Equilibrium, also in the subgame where the strategy space is given by portfolios of technologies.

In fact, any strategy profile such that one fund manager is investing in an "extreme" portfolio and the other fund manager is investing in a mix of technologies cannot be an equilibrium. The player who is holding a diversified portfolio, can optimally respond with a single technology (the same 
as his opponent's if he is the interim leader; the one that his opponent is not adopting, if he is the interim follower). If he deviates from the candidate equilibrium, his expected bonus will be the same and he will save on lexicographic costs.

Similarly we can show that we cannot have an equilibrium where both fund managers hold diversified portfolios. Suppose in fact that a fund manager is facing an opponent that is holding a diversified portfolio, then he can optimally respond to his opponent by using a single technology. Once again, his expected bonus will be the same and he will save on lexicographic costs.

Following analogous arguments we can show that fund managers optimally choose to hold "extreme" portfolios in the bonus subgame that follows symmetric play in the interim stage, and in the interim stage itself.

Clearly, if we consider a framework where fund managers are not compensated on he basis of their relative performance only, but also on account of their absolute performance, fund managers will retain some incentives to diversify. In subsection 4.1, however, we show how and to what extent our analysis might hold in such a more general setting.

\subsection{Towards a Market Model}

The model we have described in this section is extremely simple and yet seems promising. It provides an explanation of how relative performance incentives lead to herding behaviour. It allows us to characterise the resulting herding behaviour as efficient, when it occurs in the first stage of the game, and as (possibly) inefficient when it occurs in the second stage. Within this simple model we can also show how this latter type of herding outcome (herding in the bonus stage) is path dependent in a rather counterintuitive fashion. In particular, we showed that, after a good realisation of the risky technology, investors might in fact abandon it and move in a herd like manner towards the available alternative, the safe technology. Symmetrically, after a bad realisation of the risky technology, all fund managers might abandon its safer alternative. The former of these effects is well known in the empirical literature in finance as the "lock-in effect". The latter effect has also been described by the empirical literature that has often attributed it to the a supposedly irrational market "psychology".

However we would encounter serious difficulties in stretching the validity of this simple model's implications to the functioning of a financial market. This is primarily because of the fact that in the technologies' adoption model 
that we have described, rates of return $\left(A\right.$ and $\left.\widetilde{B}_{t}\right)$ are exogenously given as parameters of the model. In a financial market, on the contrary, one would expect rates of return to depend on asset prices and be, therefore a market outcome. In section 3 we try to overcome this problem, modelling a similar relative incentive structure within a competitive market, so that rates of return are endogenous. We will show that a market model retains all the interesting features of the simple model with linear technologies. In particular, we prove that inefficient herding can be observed as an equilibrium outcome. Moreover, we show that the same counterintuitive path dependency as in the model with linear technologies obtains in the market model: provided that they reach the second stage of the game with non-identical wealth, fund managers herd on the safe asset, if the risky asset just paid a high return; on the contrary, they herd on the risky asset, if it just paid a low return in the interim stage.

Moreover, in the next section we show that a market model displays a clear advantage with respect to the simple model with linear technologies. The fact that the values of $A, B^{H}$ and $B^{L}$ are not exogenous in a market model, besides from being more realistic, helps our results. In fact we are able to identify simple parametric conditions on the probability distribution of the returns of the risky asset and on the market size, such that, in the second stage of the game (and after asymmetric play in the interim stage) conditions equivalent to $A^{2}>B^{H} B^{L}$ when $\widetilde{B}_{1}=B^{H}$ in the interim stage, and $A^{2}<B^{H} B^{L}$ when $\widetilde{B}_{1}=B^{L}$ in the interim stage, are endogenously obtained. The parametric conditions needed to obtain our herding result clearly suggest that herding behaviour in the bonus stage is clearly inefficient. Namely fund managers entrust their wealth endowments to the asset that displays the lower expected rate of return. Moreover, we show that inefficient herding among fund managers occurs when the size of the rest of the market is large, but finite, so that the impact of the herd on equilibrium prices is not negligible and indeed destabilising for asset prices.

\section{A Market Model}

We consider a market where two assets are traded: a safe asset $A$ and a risky asset $B$. In each period there is one unit of each asset available: one unit of asset $A$ pays a known payoff $w_{A}$ at the end of each period, irrespective of the state of nature; one unit of asset $B$ pays $w_{B}^{H}$ with probability $p$ and 
$w_{B}^{L}$ with probability $(1-p)$. We assume that $w_{B}^{L}<w_{A}<w_{B}^{H}$. Denote the market prices of the two assets, in period $t$, by $\rho_{A t}$ and $\rho_{B t}$. (Fx-post) rates of return are:

$$
\begin{aligned}
A_{t} & =\frac{w_{A}}{\rho_{A t}} \\
B_{t}^{H} & =\frac{w_{B}^{H}}{\rho_{B t}} \\
B_{t}^{L} & =\frac{w_{B}^{L}}{\rho_{B t}}
\end{aligned}
$$

There are three different investors in this market: investors $i$ and $j$, fund managers that are motivated by relative performance incentives identical to what we described for the model with linear technologies, and a trader endowed with a logarithmic utility function which is representative of the rest of the market ${ }^{10}$. At $t=0$, the two fund managers have identical wealth endowments, which we normalise equal to 1 ; the rest of the market has wealth equal to $M$. Investing in the two available assets is the only way to store wealth, so that the entire endowment is invested in the first stage and the entire investment income obtained in the first stage is reinvested in the second stage. The objective of the two fund managers is to win the bonus at the end of the second stage; the objective of the rest of the market, in each stage, is to maximise the expected log of end of period wealth ${ }^{11}$.

All traders are price takers. However the two fund managers take their portfolio decisions strategically to outperform each other and win the bonus.

\footnotetext{
${ }^{10}$ Our choice to model the trader that is representative of the rest of the market as a logarithmic utility maximiser, finds support in the literature on survival of traders in financial markets. Logarithmic utility maximisation is the "fittest" behaviour in a risky environment: in a financial market with heterogeneous traders, logarithmic utility maximisers will dominate, determine asset prices asymptotically and drive to extinction any other trader who does not behave as a logarithmic utility maximiser, at least in the long run. See, for example, the seminal paper by Blume and Easley [4] and some recent work by Sciubba [28] and [29].

${ }^{11}$ Another clear advantage of logarithmic utility is that the "miopic" optimisation problem that we are solving period by period (maximising expected log of end of period wealth) yields the same results as a dynamic optimisation problem, over both periods and with any discount rate.
} 


\subsection{The Interim Stage}

In the interim stage, the two identical fund managers behave exactly as we have described in subsection 2.2 for the model with linear technologies. Since in case of tie nobody wins the bonus, fund managers will try and differentiate in at least one of the two stages. If they invest in the same asset in the interim stage, then only asymmetric equilibria are possible in the bonus stage. In equilibrium, the asset on which both money managers herd in the first period of play is the one with higher expected return. Nothing terribly surprising insofar.

Let us focus, instead, on asymmetric play in the interim stage. Suppose that each fund manager entrusts his wealth endowment to a different asset. Recall, in fact, from section 2.4 that, if investors only care about their ranking, they will optimally choose not to diversify and will instead hold "extreme" portfolios. Hence, one of the two money managers will demand $1 / \rho_{A, 1}$ of asset $A$; his opponent will demand $1 / \rho_{B, 1}$ of asset $B$.

The rest of the market will choose a portfolio so as to maximise the expected $\log$ of end of period wealth. At the end of the interim stage, at $t=1$, the wealth of the logarithmic trader that has chosen a portfolio with weights $\alpha_{1}$ and $\left(1-\alpha_{1}\right)$ in assets $A$ and $B$ respectively, is as follows:

$$
\widetilde{w}_{1}^{L O G}=\alpha_{1} A_{1}+\left(1-\alpha_{1}\right) \widetilde{B}_{1}
$$

where $\widetilde{B}_{1}=B_{1}^{H}$ with probability $p$ and $\widetilde{B}_{1}=B_{1}^{L}$ with probability $(1-p)$. The subscript denotes time. In this market model rates of return are time dependent as they are endogenously determined by market prices. In particular, in the interim stage:

$$
\begin{aligned}
A_{1} & =\frac{w_{A}}{\rho_{A, 1}} \\
B_{1}^{H} & =\frac{w_{B}^{H}}{\rho_{B, 1}} \\
B_{1}^{L} & =\frac{w_{B}^{L}}{\rho_{B, 1}}
\end{aligned}
$$

The logarithmic trader chooses $\alpha_{1}$ maximising $E\left[\log \widetilde{w}_{1}^{L O G}\right]$. The first order condition yields:

$$
\alpha_{1}=(1-p) \frac{B_{1}^{H}}{B_{1}^{H}-A_{1}}+p \frac{B_{1}^{L}}{B_{1}^{L}-A_{1}}
$$


Therefore, the portfolio weight invested in the risky asset can be written as:

$$
\beta_{1} \equiv\left(1-\alpha_{1}\right)=\frac{A_{1}}{\left(B_{1}^{H}-A_{1}\right)\left(A_{1}-B_{1}^{L}\right)}\left[E\left(\widetilde{B}_{1}\right)-A_{1}\right]
$$

where $E\left(\widetilde{B}_{1}\right)=p B_{1}^{H}+(1-p) B_{1}^{L}$.

\subsection{Equilibrium}

In order to solve for equilibrium prices we have to consider market demands for each asset. Asset prices (hence rates of return) will be different in the three different strategic scenarios for the two fund managers (both invest in $A$; one invests in $A$ and the other invests in $B$; both invest in $B$ ).

In what follows, we will concentrate only on those equilibrium paths that start with the two fund managers playing asymmetrically. The reason for doing so is that, when fund managers herd in the first stage, the market model adds no further insight to the analysis that we have already conducted in the previous sections for the simple model with linear technologies. Hence, let us assume that in the interim stage one of the fund managers is investing in asset $A$ and his opponent is investing in asset $B$. Moreover, since both fund managers are endowed with identical wealth, we do not need to distinguish whether it is $i$ rather than $j$ who invests in the safe as opposed to the risky asset, and viceversa: asset prices will be the same in both cases. One of the two fund managers will invest his unitary wealth in the safe asset and the other fund manager will invest his unitary wealth in the risky asset. Since they have identical wealth, the two strategic scenarios that we will observe in equilibrium display the same relative prices. Market clearing requires

$$
k_{1} \equiv \frac{\rho_{A, 1}}{\rho_{B, 1}}=\frac{\alpha_{1} M+1}{\left(1-\alpha_{1}\right) M+1}
$$

where $\alpha_{1}$ is clearly a function of the relative price of the safe asset $k_{1}$. Equilibrium in this economy requires the relative price to be market clearing and to satisfy no arbitrage. No arbitrage requires that $\forall t=1,2$ :

$$
B_{t}^{L}<A_{t}<B_{t}^{H}
$$

Simple manipulation allows us to state the following: 
Remark 1 (No arbitrage) No arbitrage in this economy is satisfied when

$$
\frac{w_{A}}{w_{B^{H}}}<k_{t}<\frac{w_{A}}{w_{B^{L}}}
$$

From equation 1 we can also claim the following:

Proposition 1 (Equilibrium in the Interim Stage) In the interim stage there is always one and only one market clearing equilibrium.

Proof. See appendix.

\subsection{The Bonus Stage}

As before, it is convenient to fix a history for the interim stage. First, consider the case $\widetilde{B}_{1}=B_{1}^{H}$, so that the fund manager who invested in the risky asset is the interim leader (call him player $i$ ) and the fund manager who invested in the safe asset is the interim follower (call him player $j)^{12}$.

If $\widetilde{B}_{1}=B_{1}^{H}$, at $t=1$ the wealth of the logarithmic trader available for investment in the bonus stage is:

$$
w_{1}^{L O G}=\alpha_{1} A_{1}+\left(1-\alpha_{1}\right) B_{1}^{H}
$$

We can easily show that the portfolio weights chosen for the bonus stage are the same as the ones chosen for the interim stage. In fact, for a logarithmic trader portfolio weights do not depend on wealth available for investment.

At the end of the second stage, at $t=2$, the logarithmic trader has wealth equal to:

$$
\widetilde{w}_{2}^{L O G}=\left[\alpha_{2} A_{2}+\left(1-\alpha_{2}\right) \widetilde{B}_{2}\right] w_{1}^{L O G}
$$

The log trader chooses $\alpha_{2}$ maximising

$$
E\left[\log \widetilde{w}_{2}^{L O G}\right]=E\left[\log \left\{\alpha_{2} A_{2}+\left(1-\alpha_{2}\right) \widetilde{B}_{2}\right\}\right]+\log w_{1}^{L O G}
$$

and as a result the level of wealth available for investment has no role in the maximisation problem (it does not appear in the first order condition).

Therefore portfolio weights as a function of asset prices are as in the interim stage:

$$
\alpha_{2}=(1-p) \frac{B_{2}^{H}}{B_{2}^{H}-A_{2}}+p \frac{B_{2}^{L}}{B_{2}^{L}-A_{2}}
$$

\footnotetext{
${ }^{12}$ Recall that we are concentrating on those equilibrium paths that start with fund managers playing asymmetrically.
} 


$$
\beta_{2} \equiv\left(1-\alpha_{2}\right)=\frac{A_{2}}{\left(B_{2}^{H}-A_{2}\right)\left(A_{2}-B_{2}^{L}\right)}\left[E\left(\widetilde{B}_{2}\right)-A_{2}\right]
$$

As a result, existence and uniqueness of market clearing equilibrium in the bonus stage and for each of the strategic scenarios for fund managers, can be proved in the same way as for the interim stage, using the no arbitrage condition.

Proposition 2 (Equilibrium in the Bonus Stage) In the bonus stage there is always one and only one market clearing equilibrium.

Proof. See appendix.

We consider now the strategic interaction between the two fund managers in the bonus stage. Consider the (asymmetric) game that follows the history $B_{1}^{H}$ in the interim stage. To find out how the bonus subgame will be played by the two fund managers we need to ask who wins the bonus under the four different strategic scenarios. No arbitrage guarantees:

$$
B_{2}^{L}<A_{2}<B_{2}^{H}
$$

1. If $A A$, then the leader ends up with wealth equal to $B_{1}^{H} A_{2}$ and the follower with wealth $A_{1} A_{2}$. Clearly the leader stays leader and wins the bonus.

2. If $B B$, then the leader ends up with wealth equal to $B_{1}^{H} \widetilde{B}_{2}$ and the follower with wealth $A_{1} \widetilde{B}_{2}$. Irrespective of the realisation of the random return, the leader stays leader and wins the bonus.

3. If $A B$ (follower in the safe, leader in the risky), then the leader ends up with wealth equal to $B_{1}^{H} \widetilde{B}_{2}$ and the follower with wealth $A_{1} A_{2}$. If $\widetilde{B}_{2}=B_{2}^{H}$, then clearly the leader gets the bonus. If $\widetilde{B}_{2}=B_{2}^{L}$, then the follower might be able to outperform the leader.

4. If $B A$ (follower in the risky, leader in the safe), then the leader ends up with wealth equal to $B_{1}^{H} A_{2}$ and the follower with wealth $A_{1} \widetilde{B}_{2}$. If $\widetilde{B}_{2}=B_{2}^{L}$, then the leader stays leader and wins the bonus. If $\widetilde{B}_{2}=B_{2}^{H}$, then the follower might be able to outperform the leader.

We want to characterise sufficient conditions so that $A A$ is a Nash Equilibrium of the bonus subgame following asymmetric play in the interim stage. 
For the interim leader, imitating the follower is always a best reply. On the contrary, the interim follower will in general have an incentive to differentiate his portfolio choice from the leader's, in order to still enjoy some positive chance of catching up. However, if the wealth gap between the two fund managers is large enough, then the interim follower has no positive chance of outperforming the leader and as a result, he will not have any incentive to deviate from our candidate equilibrium, where both fund managers invest in the safe asset. More in detail: if both fund managers invest in the safe asset, then the leader wins the bonus with probability 1 , so that the expected payoff to the follower is equal to zero. Clearly the leader has no incentive to deviate. We can show that if the risky asset pays a high payoff with a sufficiently high probability and the rest of the market is large enough, the price of the risky asset is so high that the return that the follower might get, even if he invests his whole portfolio in the risky asset and the risky asset pays a high payoff, would not be sufficient for the follower to catch up with the leader, so that in fact he has no incentive to deviate from $A A$. We can therefore state the following:

Proposition 3 (Herding in the Safe Asset: Lock-in) After a good realisation of the risky asset in the interim stage, if fund managers reach the bonus stage in "leader" and "follower" roles, if the market is large enough with respect to each of the two funds, and the probability of a good payoff from the risky asset is high enough, we obtain equilibrium herding in the safe asset. Formally, if $\widetilde{B}_{1}=B_{1}^{H}, M \geq \bar{M}$ and $p \geq \bar{p}-$ where $\bar{M}<\infty$ and $\bar{p}<1$ are defined in the appendix - then $A A$ is a Nash Equilibrium of the bonus subgame that follows $A B$ or $B A$ in the interim stage.

Proof. See appendix.

We therefore get herding in the safe asset as an equilibrium outcome of the game played by fund managers. Interestingly enough, herding in the safe asset occurs whenever it is most inefficient, i.e. when the risky asset pays a good payoff with a sufficiently high probability. In fact, proposition 2 guarantees that equilibrium prices satisfy no arbitrage, so that when the probability of a good realisation of the risky asset is high enough, despite its price being high, the expected return from the safe asset is lower than the expected return from the risky asset, so that fund managers are indeed discarding the asset with the highest expected return.

Consider now a different history for the interim stage. Keep our assumption that fund managers play asymmetrically in the interim stage. Moreover 
suppose that in the interim stage the risky asset paid a low payoff, so that $\widetilde{B}_{1}=B_{1}^{L}$. As in the previous case, in order to find out how the bonus subgame will be played we need to ask who wins the bonus under the four different strategic scenarios. No arbitrage guarantees:

$$
B_{2}^{L}<A_{2}<B_{2}^{H}
$$

1. If $A A$, then the leader ends up with wealth equal to $A_{1} A_{2}$ and the follower with wealth $B_{1}^{L} A_{2}$. Clearly the leader stays leader and wins the bonus.

2. If $B B$, then the leader ends up with wealth equal to $A_{1} \widetilde{B}_{2}$ and the follower with wealth $B_{1}^{L} \widetilde{B}_{2}$. Irrespective of the realisation of the random return, the leader stays leader and wins the bonus.

3. If $A B$ (follower in the safe, leader in the risky), then the leader ends up with wealth equal to $A_{1} \widetilde{B}_{2}$ and the follower with wealth $B_{1}^{L} A_{2}$. If $\widetilde{B}_{2}=B_{2}^{H}$, then clearly the leader gets the bonus. If $\widetilde{B}_{2}=B_{2}^{L}$, then the follower might be able to outperform the leader.

4. If $B A$ (follower in the risky, leader in the safe), then the leader ends up with wealth equal to $A_{1} A_{2}$ and the follower with wealth $B_{1}^{L} \widetilde{B}_{2}$. If $\widetilde{B}_{2}=B_{2}^{L}$, then the leader stays leader and wins the bonus. If $\widetilde{B}_{2}=B_{2}^{H}$, then the follower might be able to outperform the leader.

We want to characterise sufficient conditions such that $B B$ is a Nash Equilibrium of the bonus subgame following asymmetric play in the interim stage. The reasoning is the same as above. For the interim leader, imitating the follower is always a best reply. On the contrary, the interim follower will in general have an incentive to differentiate his portfolio choice from the leader's, in order to still enjoy some positive chance of catching up. However, if the wealth gap between the two fund managers is large enough, then the interim follower will see forgone any positive chance of outperforming the leader and as a result, he will not have any incentive to deviate from our candidate equilibrium, where both fund managers invest in the risky asset. More in detail: if both fund managers invest in the risky asset, then the leader wins the bonus with probability 1 , so that the expected payoff to the follower is equal to zero. Clearly the leader has no incentive to deviate. We show that if the risky asset pays a low payoff with a sufficiently high probability and 
the rest of the market is large enough, the price of the safe asset gets so high that the return that the follower might get, investing even a small portion of his wealth in the safe asset, would not be sufficient for the follower to catch up with the leader, not even if the leader invested his whole wealth in the risky asset and got unlucky, so that in fact the follower has no incentive to deviate from $B B$. We can therefore state the following:

Proposition 4 (Herding in the Risky Asset) After a bad realisation of the risky asset in the interim stage, if fund managers reach the bonus stage in "leader" and "follower" roles, if the market is large enough with respect to each of the two funds, and the probability of a bad payoff for the risky asset is high enough, we obtain equilibrium herding in the risky asset. Formally, if $\widetilde{B}_{1}=B_{1}^{L}, M \geq \widehat{M}$ and $p \leq \widehat{p}$ - where $\widehat{M}<\infty$ and $\widehat{p}>0$ are defined in the appendix - then $B B$ is a Nash Equilibrium of the bonus subgame, that follows $A B$ or $B A$ in the interim stage.

Proof. See appendix.

We therefore get herding in the risky asset as an equilibrium outcome of the game played by the two fund managers. Interestingly enough herding in the risky asset occurs whenever it is most inefficient, i.e. when the risky asset pays a bad payoff with a sufficiently high probability. In fact, proposition 2 guarantees that equilibrium prices satisfy no arbitrage, so that when the probability of a good realisation of the risky asset is low enough, despite its price being low, the expected return from the safe asset is higher than the expected return from the risky asset, so that fund managers are indeed discarding the asset with the highest expected return.

In summary, given some parametric conditions, inefficient herding can be observed as an equilibrium outcome, whenever fund managers are motivated by relative performance incentives. Herding occurs when the rest of the market is large enough with respect to the fund managers, but it is not necessarily infinite. As a result, the two fund managers are not negligible with respect to (the rest of) the market and their demands will significantly affect equilibrium prices. A clear consequence of inefficient herding is therefore a failure of the efficient markets hypothesis that results in excess volatility of asset prices. Figure 1, which is explained in more detail in the appendix, illustrates the impact of herding behaviour on asset prices. On the horizontal axis we represent the relative price of the safe asset with respect to the risky asset. The two vertical asymptotes of the function denoted in bold, delimite 
the range of relative prices that also satisfy no arbitrage, so that equilibrium price ratio are to be found between the two asymptotes. The intersection of the bold line with the solid line denotes equilibrium price ratio when fund managers do not herd. The intersection of the bold line with the dotted straight line denotes the equilibrium price ratio when fund managers herd on the risky asset. Finally the intersection of the bold line with the dotted curve denotes the equilibrium price ratio when fund managers herd on the safe asset.

Even just a casual comparison of the three different equilibrium price ratios shows that the herd has a non negligible impact on asset prices.

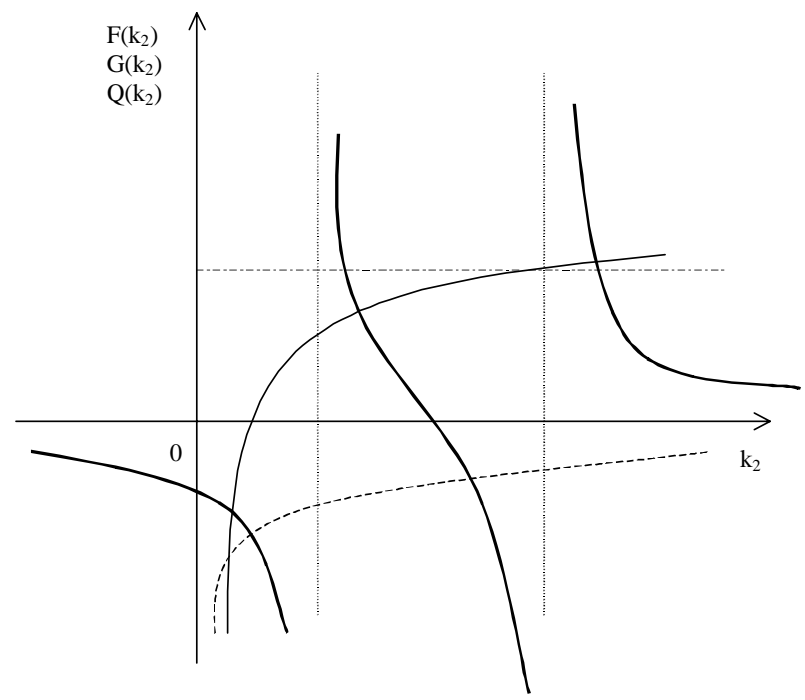

Figure 1: Impact of herding behaviour on asset prices.

\section{$4 \quad$ Extensions}

\subsection{Mixed Compensation Scheme}

One might ask what are the effects on portfolio choice and asset prices of a compensation scheme for fund managers that rewards both absolute and relative performance. We believe that our results are robust, at least to a certain extent, to such changes in the model. 
As we argued in subsection 2.4, one main consequence of partially rewarding fund managers according to their absolute performance is the fact that they would not longer choose to hold extreme portfolios, but instead diversify across the two different available assets. Provided that they are at least partially rewarded on the basis of their relative performance, in the interim stage they would still be after a leadership position, so that they would choose to hold different portfolios in the interim stage. As a result, the symmetry between the two fund managers is broken by the time they get to the end of the first stage, so that each of them reaches the bonus stage either in a leader or follower position. The wealth gap between them implies that there will still exist a set of portfolios such that the leader wins the bonus for sure and a herding equilibrium will be possible on one of such portfolios. Clearly the smaller the portion of their compensation that is based on relative, rather than absolute, performance, the closer to optimality their portfolio choice will be. So that the herding outcome will get less and less inefficient, the closer to zero the portion of their compensation linked to relative performance. However we believe that our findings on inefficient equilibrium herding would be robust, so long as fund managers receive a small, but positive, compensation for their relative performance.

\subsection{A Multiperiod Model with Endogenous Expecta- tions}

The present setting could be extended to an $n$-period model and the inefficient herding results would prove robust. In fact, in the last period (or possibly before) the fund managers would find themselves in a bonus stage game, that they would play in a similar fashion as in the last stage of a two-period model.

The possibility of obtaining robustness of our results in an $n$-period setting, leads us to what we believe is a valuable and interesting extension of our simple framework. In the present model we have assumed that everyone in the market knows the probability distribution over the payoffs of the risky asset. Suppose that the actual value for $p$, the probability that the risky asset will pay a high payoff, is not initially known. Traders start from a common prior and revise their beliefs in a Bayesian fashion, after each realisation of the risky asset. If a sufficiently long sequence of good realisations for the risky asset occurs, the belief that traders attach to a good realisation of the 
risky asset increases monotonically until it reaches the threshold level that triggers the lock-in effect: fund managers will suddenly leave the market of the risky asset. As a result, the price of that same asset that paid high payoffs and looked very promising for the future, suddenly falls. We believe that this consideration could shed some light on price crashes. In particular, it would provide an alternative explanation to Jacklin et al [18] of the fact that in the period prior to the crash, prices are higher than would be implied by fundamentals. Here, as in [18], in the period prior to the crash, asset prices are overpriced; when herding occurs, prices suddenly fall.

\section{Concluding Remarks}

We build a model of dynamic competition between money managers that are motivated by relative performance incentives. We consider a stylised financial market where two assets are traded over two periods by three agents: two fund managers and a third large trader that represents the rest of the market. Unlike the third trader, that makes his portfolio choices maximising expected utility from investment income, the two fund managers only care about their ranking, as they want to maximise the probability of obtaining a strictly positive bonus that is awarded at the end of the second period to the fund manager that displays the best cumulative performance over the two periods.

We show that inefficient herding between fund managers can be observed as equilibrium outcome in the second trading period. Our main result is to characterise sufficient conditions such that herding obtains. We show that an herd occurs when the size of the rest of the market is large, but not necessarily infinite. Hence the impact of the herd on equilibrium prices is not negligible and fund managers' behaviour is indeed destabilising for asset prices. We also prove that the direction of the herd crucially depends on funds' past performances and, in particular, on the realisation of the risky asset in the period prior to the herd. If, prior to the herd, the risky asset yields a high payoff and it is very likely to keep on yielding high payoffs in the future, then fund managers might herd on the safe asset; on the contrary, if the risky asset yields a low payoff and it is very likely to keep on yielding low payoffs in the future, then a herd might develop in the risky asset. Hence we characterise the resulting herding behaviour as inefficient: ranking-based competition between fund managers makes them withdraw funds from the most promising type of investment, the one with the highest expected return. 
Our results are consistent with the empirical observations of Brown et al [5] and Chevalier and Ellison [7]. From a theoretical perspective, our findings should be compared to Cabral [6] and Palomino and Prat [26]: our main contribution with respect to their papers is that we consider a similar incentive structure to theirs in a market setting, where we can also envisage the effects of herding behaviour on asset prices.

\section{APPENDIX}

Proof of Proposition 1 (Equilibrium in the Interim Stage). In the interim stage market clearing requires:

$$
k_{1} \equiv \frac{\rho_{A, 1}}{\rho_{B, 1}}=\frac{\alpha_{1} M+1}{\left(1-\alpha_{1}\right) M+1}
$$

where $\alpha_{1}$ and $\left(1-\alpha_{1}\right)$ are portfolio weights of the logarithmic trader in the safe and risky assets respectively. Recall that:

$$
\alpha_{1}=(1-p) \frac{B_{1}^{H}}{B_{1}^{H}-A_{1}}+p \frac{B_{1}^{L}}{B_{1}^{L}-A_{1}}
$$

which can be rewritten as follows:

$$
\alpha_{1}=(1-p) \frac{w_{B}^{H} / \rho_{B, 1}}{w_{B}^{H} / \rho_{B, 1}-w_{A} / \rho_{A, 1}}+p \frac{w_{B}^{L} / \rho_{B, 1}}{w_{B}^{L} / \rho_{B, 1}-w_{A} / \rho_{A, 1}}
$$

And finally:

$$
\alpha_{1}=(1-p) \frac{\left(w_{B}^{H} / w_{A}\right) k_{1}}{\left(w_{B}^{H} / w_{A}\right) k_{1}-1}+p \frac{\left(w_{B}^{L} / w_{A}\right) k_{1}}{\left(w_{B}^{L} / w_{A}\right) k_{1}-1}
$$

Similarly one obtains:

$$
\left(1-\alpha_{1}\right)=-(1-p) \frac{1}{\left(w_{B}^{H} / w_{A}\right) k_{1}-1}-p \frac{1}{\left(w_{B}^{L} / w_{A}\right) k_{1}-1}
$$

Hence market clearing requires:

$$
k_{1}=\frac{(1-p) \frac{\left(w_{B}^{H} / w_{A}\right) k_{1}}{\left(w_{B}^{H} / w_{A}\right) k_{1}-1} M+p \frac{\left(w_{B}^{L} / w_{A}\right) k_{1}}{\left(w_{B}^{L} / w_{A}\right) k_{1}-1} M+1}{-(1-p) \frac{1}{\left(w_{B}^{H} / w_{A}\right) k_{1}-1} M-p \frac{1}{\left(w_{B}^{L} / w_{A}\right) k_{1}-1} M+1}
$$


We can solve for equilibrium by computing the solutions of 2 , which is a third order equation in $k_{1}$. Equation 2 generally admits three solutions (i.e. three equilibria), but only one market clearing equilibrium also satisfies no arbitrage. In fact, with simple manipulation, 2 can be rewritten as:

$$
F\left(k_{1}\right)=G\left(k_{1}\right)
$$

where:

$$
\begin{aligned}
F\left(k_{1}\right) & \equiv(1-p) \frac{1+\left(w_{B}^{H} / w_{A}\right)}{\left(w_{B}^{H} / w_{A}\right) k_{1}+1}+p \frac{1+\left(w_{B}^{L} / w_{A}\right)}{\left(w_{B}^{L} / w_{A}\right) k_{1}+1} \\
G\left(k_{1}\right) & \equiv \frac{1}{M} \cdot \frac{k_{1}-1}{k_{1}}
\end{aligned}
$$

We can plot $F\left(k_{1}\right)$ and $G\left(k_{1}\right)$ on a diagram (figure 2 ), to obtain a geometrical proof of our claim. The solid line is $F\left(k_{1}\right)$ and the dotted line is $G\left(k_{1}\right)$.

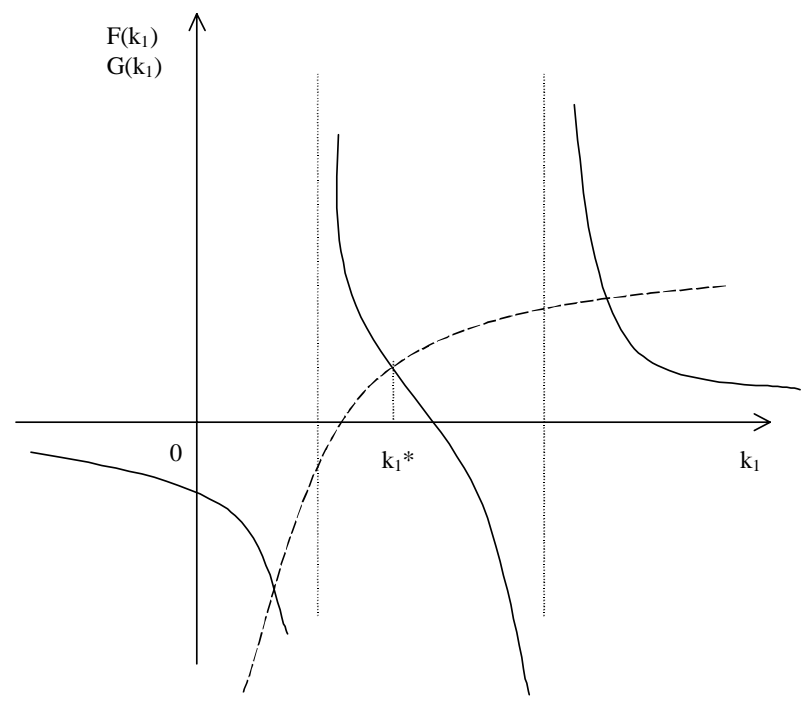

Figure 2: Market clering in the interim stage.

They intersect three times; however only one intersection corresponds to a price ratio such that no arbitrage is guaranteed: $F\left(k_{1}\right)$ has two vertical asymptotes in $w_{A} / w_{B}^{H}$ and in $w_{A} / w_{B}^{L}$. From remark 1 , we know that a price 
ratio satisfying no arbitrage has to be such that: $w_{A} / w_{B}^{H}<k_{t}<w_{A} / w_{B}^{L}$, so that the only price ratio that at the same time clears the markets and satisfies no arbitrage in the interim stage is $k_{1}^{*}$ (as denoted on the diagram in figure 2).

Proof of Proposition 2 (Equilibrium in the Bonus Stage). In the bonus stage, when the two fund managers operate in different markets (i.e. each of them invests in a different asset), the proof is identical to the proof of proposition 1 . When both fund managers invest in the risky asset, market clearing requires:

$$
k_{2}=\frac{(1-p) \frac{\left(w_{B}^{H} / w_{A}\right) k_{2}}{\left(w_{B}^{H} / w_{A}\right) k_{2}-1} w_{1}^{L O G}+p \frac{\left(w_{B}^{L} / w_{A}\right) k_{2}}{\left(w_{B}^{L} / w_{A}\right) k_{2}-1} w_{1}^{L O G}}{-(1-p) \frac{1}{\left(w_{B}^{H} / w_{A}\right) k_{2}-1} w_{1}^{L O G}-p \frac{1}{\left(w_{B}^{L} / w_{A}\right) k_{2}-1} w_{1}^{L O G}+\left(w_{1}^{L}+w_{1}^{F}\right)}
$$

where $w_{1}^{L O G}, w_{1}^{L}$ and $w_{1}^{F}$ are respectively the investment incomes of the rest of the market, the leader and the follower at the end of the interim stage. Equation 3 admits only one solution that also satisfies no arbitrage. In fact, with simple manipulation, 3 can be rewritten as:

$$
F\left(k_{2}\right)=G \equiv \frac{w_{1}^{L}+w_{1}^{F}}{w_{1}^{L O G}}
$$

where:

$$
F\left(k_{2}\right) \equiv(1-p) \frac{1+\left(w_{B}^{H} / w_{A}\right)}{\left(w_{B}^{H} / w_{A}\right) k_{2}+1}+p \frac{1+\left(w_{B}^{L} / w_{A}\right)}{\left(w_{B}^{L} / w_{A}\right) k_{2}+1}
$$

We can plot $F\left(k_{2}\right)$ on a diagram (see figure 3 ), to obtain a geometrical proof of our claim. The solid line is $F\left(k_{2}\right)$, which equals $G$ twice; $F\left(k_{2}\right)$ has two vertical asymptotes in $w_{A} / w_{B}^{H}$ and in $w_{A} / w_{B}^{L}$. From remark 1 , we know that a price ratio satisfying no arbitrage has to be such that: $w_{A} / w_{B}^{H}<k_{t}<$ $w_{A} / w_{B}^{L}$, so that the only price ratio that at the same time clears the markets and satisfies no arbitrage in the bonus stage is $k_{2}^{*}$ (as denoted on the diagram in figure 3). Similarly one can show that one and only one equilibrium exists when both fund managers invest in the safe asset. Market clearing requires:

$$
k_{2}=\frac{(1-p) \frac{\left(w_{B}^{H} / w_{A}\right) k_{2}}{\left(w_{B}^{H} / w_{A}\right) k_{2}-1} w_{1}^{L O G}+p \frac{\left(w_{B}^{L} / w_{A}\right) k_{2}}{\left(w_{B}^{L} / w_{A}\right) k_{2}-1} w_{1}^{L O G}+\left(w_{1}^{L}+w_{1}^{F}\right)}{-(1-p) \frac{1}{\left(w_{B}^{H} / w_{A}\right) k_{2}-1} w_{1}^{L O G}-p \frac{1}{\left(w_{B}^{L} / w_{A}\right) k_{2}-1} w_{1}^{L O G}}
$$




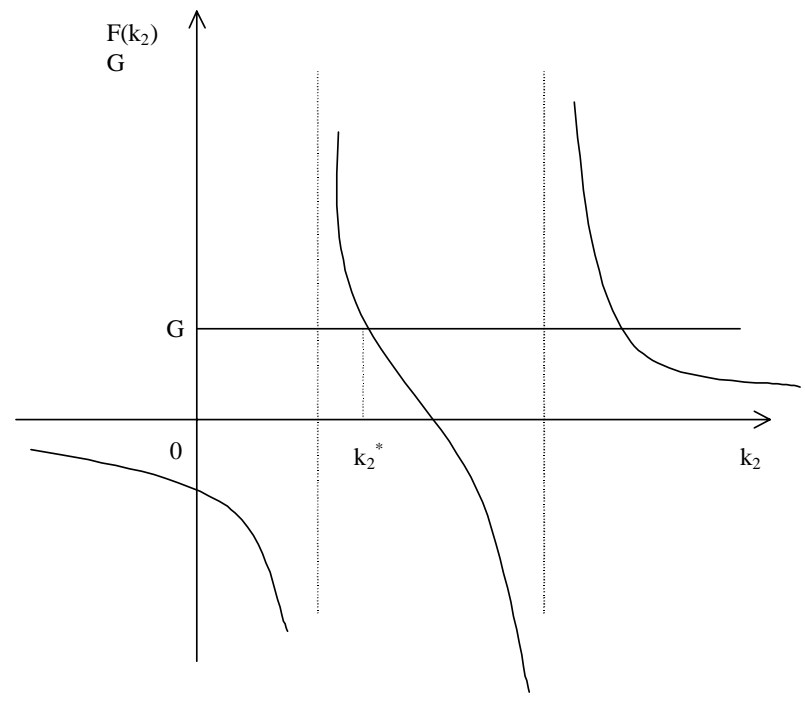

Figure 3: Herd in the risky asset: market clearing.

Equation 4 admits only one solution that also satisfies no arbitrage. In fact, with simple manipulation, 4 can be rewritten as:

$$
F\left(k_{2}\right)=Q\left(k_{2}\right)
$$

where:

$$
\begin{aligned}
F\left(k_{2}\right) & \equiv(1-p) \frac{1+\left(w_{B}^{H} / w_{A}\right)}{\left(w_{B}^{H} / w_{A}\right) k_{2}+1}+p \frac{1+\left(w_{B}^{L} / w_{A}\right)}{\left(w_{B}^{L} / w_{A}\right) k_{2}+1} \\
Q\left(k_{2}\right) & =-\frac{w_{1}^{L}+w_{1}^{F}}{w_{1}^{L O G} k_{2}}
\end{aligned}
$$

We can plot $F\left(k_{2}\right)$ and $Q\left(k_{2}\right)$ on a diagram (see figure 4 ), to obtain a geometrical proof of our claim. The solid line in the diagram is $F\left(k_{2}\right)$, while the dotted line is $Q\left(k_{2}\right)$. They intersect twice; $F\left(k_{2}\right)$ has two vertical asymptotes in $w_{A} / w_{B}^{H}$ and in $w_{A} / w_{B}^{L}$. From remark 1 , we know that a price ratio satisfying no arbitrage has to be such that: $w_{A} / w_{B}^{H}<k_{t}<w_{A} / w_{B}^{L}$, so that the only price ratio that clear the markets and satisfies no arbitrage in the bonus stage is $k_{2}^{*}$ (as denoted on the diagram in figure 4). Finally, in figure 5, we compare equilibrium prices when fund managers herd and do 


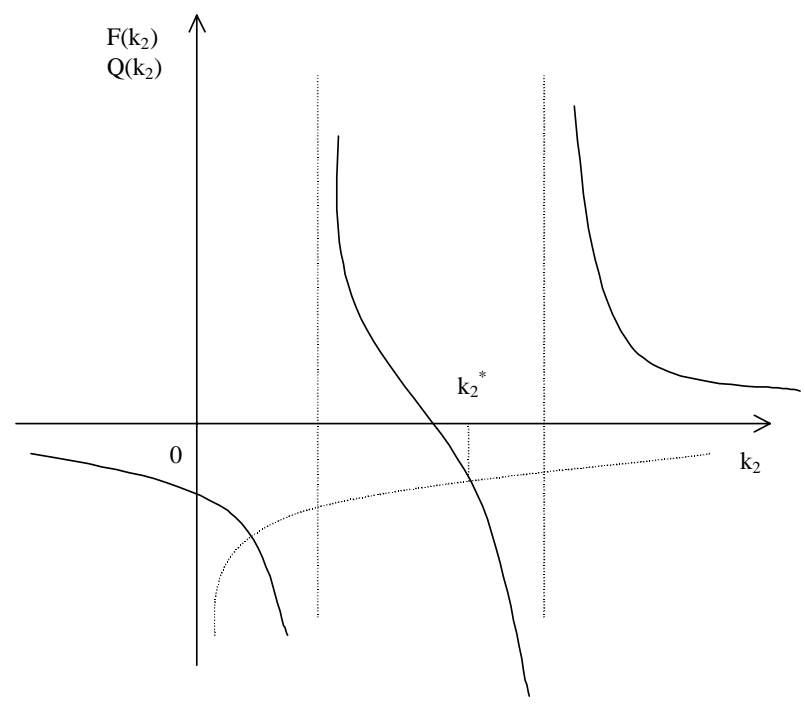

Figure 4: Herd in the safe asset: market clearing.

not herd: the bold line represents $F\left(k_{2}\right)$; the dotted lines in the diagram represent $G$ and $Q\left(k_{2}\right)$ and correspond to a situation where fund managers herd; the solid line represents $G\left(k_{2}\right)$ and corresponds to a situation where fund managers do not herd. We can notice that price ratios are different in the three situations: herding behaviour drives equilibrium prices away from fundamentals.

Proof of Proposition 3 (Herding in the Safe Asset: Lock-in). We want to characterise conditions such that $A A$ is a Nash Equilibrium of the bonus game, after $\widetilde{B}_{1}=B_{1}^{H}$ in the interim stage. Consider the interim leader first: if he does not deviate, his expected payoff is 1 , since he is guaranteed to keep his leadership and win the bonus; clearly he has no incentive to deviate. Consider now the follower: if he does not deviate, his expected payoff is zero; he will deviate, if he can do better than zero. If the follower deviates from $A A$, then the strategy profile becomes $B A$ : the performance of the interim follower is $A_{1} \widetilde{B}_{2}$, while the performance of the interim leader is $B_{1}^{H} A_{2}$; in fact, if $\widetilde{B}_{1}=B_{1}^{H}$, then it must be the case that, in the interim stage, interim leader and follower invested respectively in the risky and safe asset. If $\widetilde{B}_{2}=B_{2}^{L}$, then clearly:

$$
A_{1} \widetilde{B}_{2}=A_{1} B_{2}^{L}<B_{1}^{H} A_{2}
$$




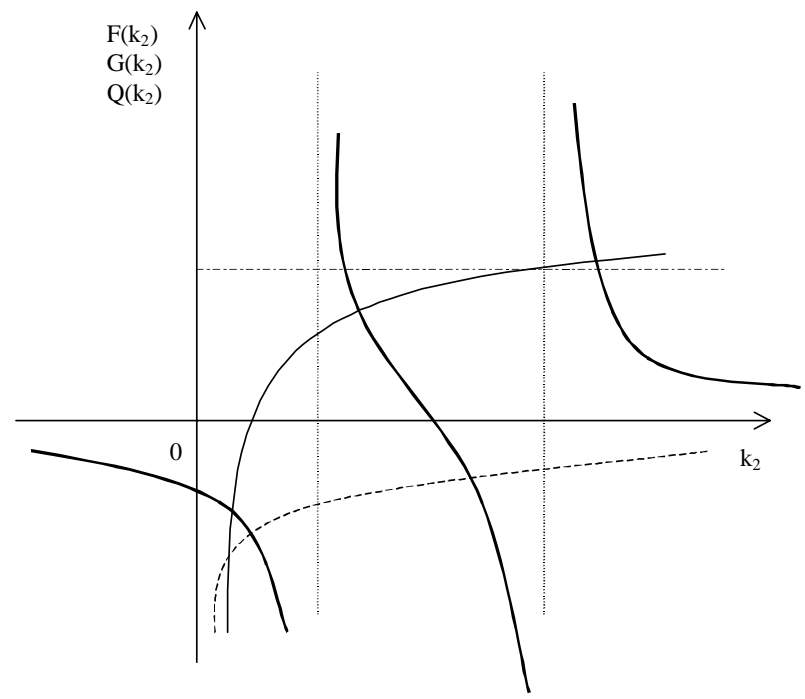

Figure 5: Impact of herding behaviour on asset prices.

so that the leader stays leader and wins the bonus with probability one. Hence, when $\widetilde{B}_{2}=B_{2}^{L}$, the interim follower has no incentive to deviate from our candidate equilibrium. As a result, the only situation in which the interim follower might indeed obtain a strictly positive payoff is the case $\widetilde{B}_{2}=B_{2}^{H}$. It is sufficient to have:

$$
A_{1} B_{2}^{H} \leq B_{1}^{H} A_{2}
$$

to guarantee that the interim follower has no incentive to deviate from the candidate equilibrium. Simple manipulation shows that 5 is equivalent to:

$$
k_{2} \leq k_{1}
$$

where $k_{t} \equiv \rho_{A, t} / \rho_{B, t}$. Recall that, when in the interim stage $\widetilde{B}_{1}=B_{1}^{H}$ and in the bonus stage the strategy profile is $B A$ (follower in the risky, leader in the safe), by simple market clearing:

$$
k_{2}=\frac{\alpha_{2} M^{\prime}+B_{1}^{H}}{\left(1-\alpha_{2}\right) M^{\prime}+A_{1}}
$$

where:

$$
M^{\prime}=\alpha_{1} A_{1} M+\left(1-\alpha_{1}\right) B_{1}^{H} M
$$


Substituting 8 into 7 , we find that condition 6 requires:

$$
\frac{\alpha_{1} \alpha_{2} M+\left(1-\alpha_{1}\right) \alpha_{2}\left(w_{B}^{H} / w_{A}\right) k_{1} M+\left(w_{B}^{H} / w_{A}\right) k_{1}}{\alpha_{1}\left(1-\alpha_{2}\right) M+\left(1-\alpha_{1}\right)\left(1-\alpha_{2}\right)\left(w_{B}^{H} / w_{A}\right) k_{1} M+1} \leq k_{1}
$$

We can express 9 as an inequality for $M$ as:

$$
\left[\left(1-\alpha_{1}\right)\left(w_{B}^{H} / w_{A}\right) k_{1}+\alpha_{1}\right]\left[\left(1-\alpha_{2}\right) k_{1}-\alpha_{2}\right] M \geq\left[\left(w_{B}^{H} / w_{A}\right)-1\right] k_{1}
$$

Inequality 10 is satisfied when both:

$$
\left(1-\alpha_{2}\right) k_{1}-\alpha_{2}>0
$$

and:

$$
M \geq \bar{M} \equiv \frac{\left[\left(w_{B}^{H} / w_{A}\right)-1\right] k_{1}}{\left[\left(1-\alpha_{1}\right)\left(w_{B}^{H} / w_{A}\right) k_{1}+\alpha_{1}\right]\left[\left(1-\alpha_{2}\right) k_{1}-\alpha_{2}\right]}
$$

The last step in our proof is to find conditions such that 11 is satisfied. Recall that by no arbitrage $k_{1}$ is bounded below by $w_{A} / w_{B}^{H}$. Hence:

$$
\left(1-\alpha_{2}\right) k_{1}-\alpha_{2}>\left(1-\alpha_{2}\right) \frac{w_{A}}{w_{B}^{H}}-\alpha_{2}=\frac{w_{A}}{w_{B}^{H}}-\alpha_{2}\left(\frac{w_{A}}{w_{B}^{H}}+1\right)
$$

It follows that 11 is necessarily satisfied when:

$$
\frac{w_{A}}{w_{B}^{H}}-\alpha_{2}\left(\frac{w_{A}}{w_{B}^{H}}+1\right) \geq 0
$$

which can be reformulated as:

$$
\alpha_{2} \leq \frac{w_{A}}{w_{A}+w_{B}^{H}}
$$

We can finally show that a sufficiently large value for $p$ implies 13 , and a fortiori 11. Recall that:

$$
\alpha_{2}=(1-p) \frac{w_{B}^{H} k_{2}}{w_{B}^{H} k_{2}-w_{A}}-p \frac{w_{B}^{L} k_{2}}{w_{B}^{L} k_{2}-w_{A}}
$$

so that 13 can be rewritten as:

$$
(1-p) \frac{w_{B}^{H} k_{2}}{w_{B}^{H} k_{2}-w_{A}}-p \frac{w_{B}^{L} k_{2}}{w_{B}^{L} k_{2}-w_{A}} \leq \frac{w_{A}}{w_{A}+w_{B}^{H}}
$$


which implies:

$$
p \geq \bar{p} \equiv \frac{\left(w_{B}^{H} k_{2}\right) /\left(w_{B}^{H} k_{2}-w_{A}\right)-w_{A} /\left(w_{A}+w_{B}^{H}\right)}{\left(w_{B}^{H} k_{2}\right) /\left(w_{B}^{H} k_{2}-w_{A}\right)+\left(w_{B}^{L} k_{2}\right) /\left(w_{B}^{L} k_{2}-w_{A}\right)}
$$

Summarising: $p \geq \bar{p}$ and $M \geq \bar{M}$ guarantee that 6 , and hence 5 are satisfied, so that the interim follower has no incentive to deviate from the candidate equilibrium. Notice that $\bar{p}<1$ and $\bar{M}<\infty$, so that parameter values such that the conditions we pose are satisfied indeed exist.

Proof of Proposition 4 (Herding in the Risky Asset). We want to characterise conditions such that $B B$ is a Nash Equilibrium of the bonus game, after $\widetilde{B}_{1}=B_{1}^{L}$ in the interim stage. Consider the interim leader first: if he does not deviate, his expected payoff is 1 , since he is guaranteed to keep his leadership and win the bonus; clearly he has no incentive to deviate. Consider now the follower: if he does not deviate, his expected payoff is zero; he will deviate if he can do better than zero. If the follower deviates from $B B$, then the strategy profile becomes $A B$ : the performance of the interim follower is $B_{1}^{L} A_{2}$, while the performance of the interim leader is $A_{1} \widetilde{B}_{2}$; in fact, if $\widetilde{B}_{1}=B_{1}^{L}$, then it must be the case that, in the interim stage, interim leader and follower invested respectively in the safe and risky asset. If $\widetilde{B}_{2}=B_{2}^{H}$, then clearly:

$$
A_{1} \widetilde{B}_{2}=A_{1} B_{2}^{H}>B_{1}^{L} A_{2}
$$

so that the leader stays leader and wins the bonus with probability one. Hence, when $\widetilde{B}_{2}=B_{2}^{H}$, the interim follower has no incentive to deviate from the candidate equilibrium. As a result, the only situation in which the interim follower might outperform the leader and gain a strictly positive payoff, is the case $\widetilde{B}_{2}=B_{2}^{L}$. It is sufficient to have:

$$
A_{1} B_{2}^{L} \geq B_{1}^{L} A_{2}
$$

to guarantee that the interim follower has no incentive to deviate from the candidate equilibrium. Simple manipulation shows that 15 is equivalent to:

$$
k_{1} \leq k_{2}
$$

where $k_{t} \equiv \rho_{A, t} / \rho_{B, t}$. Recall that, when in the interim stage $\widetilde{B}_{1}=B_{1}^{L}$ and in the bonus stage the strategy profile is $A B$ (follower in the safe, leader in the risky), by simple market clearing:

$$
k_{2}=\frac{\alpha_{2} M^{\prime}+B_{1}^{L}}{\left(1-\alpha_{2}\right) M^{\prime}+A_{1}}
$$


where:

$$
M^{\prime}=\alpha_{1} A_{1} M+\left(1-\alpha_{1}\right) B_{1}^{L} M
$$

Substituting 18 into 17, we find that condition 16 requires:

$$
\frac{\alpha_{1} \alpha_{2} M+\left(1-\alpha_{1}\right) \alpha_{2}\left(w_{B}^{L} / w_{A}\right) k_{1} M+\left(w_{B}^{L} / w_{A}\right) k_{1}}{\alpha_{1}\left(1-\alpha_{2}\right) M+\left(1-\alpha_{1}\right)\left(1-\alpha_{2}\right)\left(w_{B}^{L} / w_{A}\right) k_{1} M+1} \geq k_{1}
$$

We can express 19 as an inequality for $M$ as:

$$
\left[\left(1-\alpha_{1}\right)\left(w_{B}^{L} / w_{A}\right) k_{1}+\alpha_{1}\right]\left[\alpha_{2}-\left(1-\alpha_{2}\right) k_{1}\right] M \geq\left[1-\left(w_{B}^{L} / w_{A}\right)\right] k_{1}
$$

Inequality 20 is satisfied when both:

$$
\alpha_{2}-\left(1-\alpha_{2}\right) k_{1}>0
$$

and:

$$
M \geq \widehat{M} \equiv \frac{\left[1-\left(w_{B}^{L} / w_{A}\right)\right] k_{1}}{\left[\left(1-\alpha_{1}\right)\left(w_{B}^{L} / w_{A}\right) k_{1}+\alpha_{1}\right]\left[\alpha_{2}-\left(1-\alpha_{2}\right) k_{1}\right]}
$$

The last step in our proof is to find conditions such that 21 is satisfied. Recall that by no arbitrage $k_{1}$ is bounded above by $w_{A} / w_{B}$. Hence:

$$
\alpha_{2}-\left(1-\alpha_{2}\right) k_{1}>\alpha_{2}-\left(1-\alpha_{2}\right) \frac{w_{A}}{w_{B}^{L}}=\alpha_{2}\left(\frac{w_{A}}{w_{B}^{L}}+1\right)-\frac{w_{A}}{w_{B}^{L}}
$$

It follows that 21 is necessarily satisfied when:

$$
\alpha_{2}\left(\frac{w_{A}}{w_{B}^{L}}+1\right)-\frac{w_{A}}{w_{B}^{L}} \geq 0
$$

which can be reformulated as:

$$
\alpha_{2} \geq \frac{w_{A}}{w_{A}+w_{B}^{L}}
$$

We can finally show that a sufficiently small value for $p$ implies 23 , and a fortiori 21. Recall that:

$$
\alpha_{2}=(1-p) \frac{w_{B}^{H} k_{2}}{w_{B}^{H} k_{2}-w_{A}}-p \frac{w_{B}^{L} k_{2}}{w_{B}^{L} k_{2}-w_{A}}
$$


so that 23 can be rewritten as:

$$
(1-p) \frac{w_{B}^{H} k_{2}}{w_{B}^{H} k_{2}-w_{A}}-p \frac{w_{B}^{L} k_{2}}{w_{B}^{L} k_{2}-w_{A}} \geq \frac{w_{A}}{w_{A}+w_{B}^{L}}
$$

which implies:

$$
p \leq \hat{p} \equiv \frac{\left(w_{B}^{H} k_{2}\right) /\left(w_{B}^{H} k_{2}-w_{A}\right)-w_{A} /\left(w_{A}+w_{B}^{L}\right)}{\left(w_{B}^{H} k_{2}\right) /\left(w_{B}^{H} k_{2}-w_{A}\right)+\left(w_{B}^{L} k_{2}\right) /\left(w_{B}^{L} k_{2}-w_{A}\right)}
$$

Summarising: $p \leq \hat{p}$ and $M \geq \widehat{M}$ guarantee that 16 , and hence 15 are satisfied, so that the interim follower has no incentive to deviate from our candidate equilibrium. Notice that $\hat{p}>0$ and $\widehat{M}<\infty$, so that parameter values such that the conditions we pose are satisfied indeed exist. 


\section{References}

[1] Ashton, D., M. Crossland and P. Moizer (1990), The Performance Evaluation of Fund Managers, mimeo.

[2] Banca d'Italia (1998), Relazione Annuale del Governatore.

[3] Bikhchandani, S., D. Hirshleifer and I. Welch (1992), A Theory of Fads, Fashion, Custom and Cultural Change as Informational Cascades, Journal of Political Economy 100, 992-1026.

[4] Blume L. and D. Easley (1992), Evolution and Market Behaviour, Journal of Economic Theory 26, 318-339.

[5] Brown, K.C., W.V. Harlow and L.T. Starks (1996), Of Tournaments and Temptations: an Analysis of Managerial Incentives in the Mutual Fund Industry, Journal of Finance 51, 85-110.

[6] Cabral, L.M.B. (1999), Football, Sailing, and R\&D: Dynamic Competition with Strategic Choice of Variance and Covariance, mimeo.

[7] Chevalier, J. and G. Ellison (1997), Risk Taking by Mutual Funds as a Response to Incentives, Journal of Political Economy 105, 1167-1200.

[8] Cutler, D.M., J.M. Poterba and L.H. Summers (1990), Speculative Dynamics and the Role of Feedback Traders, American Economic Review $80,63-68$.

[9] De Long, J.B., A. Shleifer, L.H. Summers and R.J. Waldman (1990), Positive Feedback Investment Strategies and Destabilising Rational Speculation, Journal of Finance 45, 379-395 .

[10] Eichberger, J., S. Grant and S.P. King (1997), On Relative Performance and Fund Manager's Incentives, The Australian National University Working Paper n. 327.

[11] Frankel, J.A. and K.A. Froot (1990), Chartists, Fundamentalists, and Trading in the Foreign Exchange Market, American Economic Review $80,181-185$.

[12] Gennotte, G. and H. Leland (1990), Market Liquidity, Hedging and Crashes, American Economic Review 80, 999-1021. 
[13] Gibbons, R. and K.J. Murphy (1989), Relative Performance Evaluation for Chief Executive Officers, NBER Working Paper n. 2944.

[14] Grinblatt, M., S. Titman and R. Wermers (1995), Momentum Investment Strategies, Portfolio Performance, and Hedging: a Study of Mutual Fund Behaviour, American Economic Review 85, 1088-1105.

[15] Gümbel, A. (1998), Herding in Delegated Portfolio Management. When is Comparative Performance Information Desirable?, European University Institute Working Paper n. 98/22.

[16] Hvide, H.K. (1999), Tournament Rewards and Risk Taking, mimeo.

[17] Hvide, H.K. and E.G. Kristiansen (1999), Risk Taking in Selection Contests, mimeo.

[18] Jacklin, C.J., A.W. Kleidon and P. Pfleiderer (1992), Underestimation of Portfolio Insurance and the Crash of October 1987, Review of Financial Studies 5, 35-63.

[19] Keynes, John M.(1936), The General Theory of Employment, Interest and Money, MacMillan, London.

[20] Lakonishock, J., A. Shleifer and R.W. Vishny (1992), The Impact of Institutional Trading on Stock Prices, Journal of Finance 32, 23-43.

[21] Meyer, M.A. and J. Vickers (1997), Performance Comparisons and Dynamic Incentives, Journal of Political Economy 105, 547-581.

[22] Mookherjee, D. (1984), Optimal Incentive Schemes with Many Agents, Review of Economic Studies 51, 433-446.

[23] Nalebuff, B.J. and J.E. Stiglitz (1983), Prizes and Incentives: Towards a General Theory of Compensation and Competition, Bell Journal of Economics 14, 21-43.

[24] New York Stock Fxchange (1998), Fact Book.

[25] Palomino, F. and A. Prat (1999), Risk Taking and Optimal Contracts for Money Managers, mimeo. 
[26] Palomino, F. and A. Prat (1998), Dynamic Incentives in the Money Management Tournament, mimeo.

[27] Scharfstein, D.S. and J.C. Stein (1990), Herd Behaviour and Investment, American Economic Review 80, 465-479.

[28] Sciubba, E. (1999), The Evolution of Portfolio Rules and the Capital Asset Pricing Model, University of Cambridge, DAE Working Paper n. 9907.

[29] Sciubba, E. (1999), Asymmetric Information and Survival in Financial Markets, University of Cambridge, DAE Working Paper n. 9908.

[30] Welch, I. (1992), Sequential Sales, Learning and Cascades, Journal of Finance 47, 695-732.

[31] Zwiebel, J. (1995), Corporate Conservatism and Relative Compensation, Journal of Political Economy 103, 1-25. 